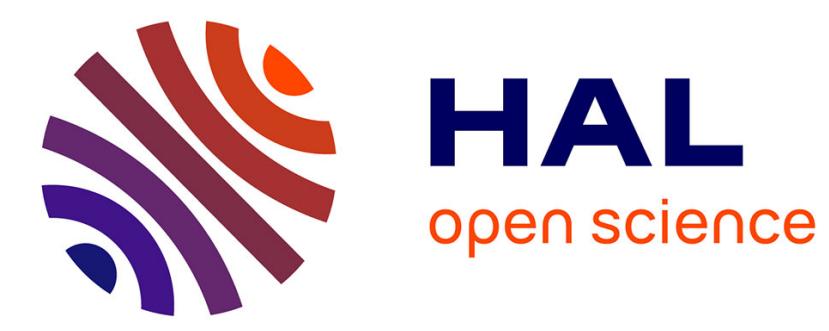

\title{
Propagation of ultrasonic pulses through trabecular bone
}

\author{
W. Lauriks, J. Thoen, I. van Asbroeck, G. Lowet, G. van Der Perre
}

\section{To cite this version:}

W. Lauriks, J. Thoen, I. van Asbroeck, G. Lowet, G. van Der Perre. Propagation of ultrasonic pulses through trabecular bone. Journal de Physique IV Proceedings, 1994, 04 (C5), pp.C5-1255-C5-1258. 10.1051/jp4:19945278 . jpa-00252969

\section{HAL Id: jpa-00252969 https://hal.science/jpa-00252969}

Submitted on 1 Jan 1994

HAL is a multi-disciplinary open access archive for the deposit and dissemination of scientific research documents, whether they are published or not. The documents may come from teaching and research institutions in France or abroad, or from public or private research centers.
L'archive ouverte pluridisciplinaire HAL, est destinée au dépôt et à la diffusion de documents scientifiques de niveau recherche, publiés ou non, émanant des établissements d'enseignement et de recherche français ou étrangers, des laboratoires publics ou privés. 


\title{
Propagation of ultrasonic pulses through trabecular bone
}

\author{
W. LAURIKS, J. THOEN, I. VAN ASBROECK, G. LOWET* and G. VAN DER PERRE*
}

Laboratorium voor Akoestiek en Warmtegeleiding, Departement Natuurkunde, Katholieke Universiteit Leuven, Celestijnenlaan 200D, 3001 Heverlee, Belgium

* Afdeling Biomechanica en Grafisch Ontwerpen, Departement Werktuigkunde, Katholieke Universiteit Leuven, Celestijnenlaan 200A, 3001 Heverlee, Belgium

\begin{abstract}
It is shown that the transmission of ultrasonic pulses in bovine trabecular bone can be adequately described using Biot's theory. The different parameters involved in this theory have been measured independently and the theoretical results have been compared with experimental data obtained on water filled samples. Although several assumptions and approximations had to be made, the correspondence between theory and experiment is satisfactory.
\end{abstract}

\section{Introduction}

Ultrasonic sound velocity in bone is usually modeled by assuming the bone to be an isotropic elastic solid. In this case the longitudinal velocity is determined by the elastic constants of the bone and its density. Trabecular bone, however, can be highly porous and the interaction between the porous structure and the liquid in the bone should be taken into account. Biot's theory ${ }^{1,2,3}$ describes sound propagation through liquid filled porous media as a function of various structural parameters. The theory predicts the existence of two longitudinal waves (one of which is highly attenuated) and a shear wave. The two compressional waves have been observed experimentally in different materials including sintered glass beads ${ }^{4}$, plastic foams ${ }^{5}$ and human and bovine bone ${ }^{6}$. Recently, the Biot theory has been used to predict the sound propagation through trabecular bone $^{7}$. However, functional relations have been used between the structural parameters and the elastic modulus and the porosity and no attempt has been made to measure them independently. Moreover, viscous attenuation has not been taken into account.

In this paper, the different structural parameters of 8 samples of bovine trabecular bone are measured independently. It is shown that the theoretical results correlate with experimental data for water saturated samples, obtained with an ultrasonic pulse transmission method.

\section{Biot's theory}

M.A. Biot proposed a semi-phenomenological theory for sound propagation in liquid filled porous media that are macroscopically isotropic. A consequence of this theory is the prediction of a fast compressional wave where the fluid and the solid part of the material move in phase and a slow compressional wave where they move in phase opposition. Due to the high velocity difference between frame and liquid, the slow wave will be highly attenuated and is often difficult to observe. The velocities of the fast and the slow compressional wave are given by : 


$$
V_{F, S}^{2}=\Delta \pm \frac{\sqrt{\Delta^{2}-4\left(\tilde{\rho}_{11} \tilde{\rho}_{22}-\tilde{\rho}_{12}^{2}\right)\left(P R-Q^{2}\right)}}{2\left(\tilde{\rho}_{11} \tilde{\rho}_{22}-\tilde{\rho}_{12}^{2}\right)}, \quad \Delta=P \tilde{\rho}_{11}+R \tilde{\rho}_{11}-2 \tilde{\rho}_{12} Q
$$

In this equation, the $\tilde{\rho}_{i j}$ are density terms given by:

$$
\tilde{\boldsymbol{\rho}}_{11}(\omega)+\tilde{\boldsymbol{\rho}}_{12}(\omega)=(1-h) \boldsymbol{\rho}_{s}, \quad \tilde{\boldsymbol{\rho}}_{22}(\omega)+\tilde{\rho}_{12}(\omega)=h \rho_{f}, \quad \tilde{\rho}_{12}(\omega)=-(\tilde{\alpha}(\omega)-1) h \rho_{f},
$$

where $\rho_{\mathrm{s}}$ is the density of the frame material and $\rho_{\mathrm{f}}$ the density of the fluid in the pores. $h$ is the porosity, i.e. the percentage of liquid in the material and $\alpha(\omega)$ is given by:

$\tilde{\alpha}(\omega)=\alpha+\frac{\eta h}{i \omega b} F(\omega)$,

where $\alpha$ is a parameter, called the tortuosity factor which is a purely geometrical factor always larger than 1 . The factor $b$ is the permeability (viscous drag) of the porous material and $F(\omega)$ is a function that accounts for the frequency dependence of the microscopic fluid flow patterns in the pores. The simplest expression of $F(\omega)$ is given by ${ }^{3}$ :

$F(\omega)=\left(1-\frac{4 i \alpha^{2} b^{2} \rho_{0} \omega}{\eta \Lambda^{2} h^{2}}\right)^{1 / 2}, \quad \lambda=C(8 \alpha b / h)^{1 / 2}$.

$C$ is a parameter of order 1 which accounts for the shape of the pores. $\eta$ is the viscosity of the liquid. $\mathrm{P}, \mathrm{Q}$ and $\mathrm{R}$ in equation (1) are three phenomenological parameters. Biot succeeded in relating these parameters to independently measurable quantities by use of "gedanken"experiments. These three parameters can be expressed as a function of the bulk modulus of the frame material $\mathrm{K}_{\mathrm{S}}$ (i.e. the bulk modulus of the solid bone filaments making the frame), the bulk modulus of the frame $\mathrm{K}_{\mathrm{b}}$, the modulus of the fluid $\mathrm{K}_{\mathrm{g}}$ and the shear modulus of the frame $\mathrm{N}$. We now assume that when a bone sample is compressed, this results in a bending and displacing of the bone filaments and not in a compression of the bone material itself. This is a reasonable assumption for highly porous materials. In this case, the bulk modulus of the frame material is much higher than the bulk modulus of the frame and the relations for $\mathrm{P}, \mathrm{Q}$, and $\mathrm{R}$ become :

$$
P=K_{b}+\frac{4}{3} N+\frac{(1-h)^{2}}{h} K_{f}, \quad Q=(1-h) K_{f}, \quad R=h K_{f} .
$$

In the next paragraph, we will explain how the different parameters can be measured independently.

\section{Determination of the material parameters}

The porosity of a porous sample can be determined in different ways. If the material can easily be saturated with a liquid, the simplest method to measure $h$ is to measure the change in height of a water column in a recipient when the sample is immersed and all the air is drained from the pores.

If all the pores are interconnected and if no closed cells are present, the density of the frame material can be determined from the apparent density of the porous material.

The tortuosity is an important parameter in the Biot theory and determines the mass coupling between fluid and solid. It expresses the sinuosity and change in diameter of the pores. The tortuosity can be measured with the experimental setup described in ref 3 . The sample is saturated with a conducting liquid (e.g. a saline water solution). A small electrical current is directed through the sample and the potential difference across the sample is registered. The tortuosity is than given by $\alpha=h \sigma_{s} / \sigma_{f}$, with $\sigma_{s}$ the electric conductivity of the sample filled with the conducting liquid and $\sigma_{\mathrm{f}}$ the conductivity of the liquid. 
The equations 2 to 5 incorporate a coefficient $b$ which accounts for the viscous drag between the solid frame and the liquid. It can be measured with the following method. The sample is attached under a tube filled with water. When the liquid can flow freely, the height of the water column as a function of time is given by $h=h_{0} \operatorname{Exp}\left(-\rho g A t / b A_{o} d\right)$ where $\mathrm{h}_{\mathrm{o}}$ is the height of the water column at $t=0, p$ is the density of water, $g$ the gravitational constant, $d$ the thickness of the sample and $A$ and $A_{o}$ the areas of the tube and the sample respectively. The parameter $b$ governs the attenuation in the material, but it is less important for the velocity of the fast wave. The Biot theory also requires a phenomenological parameter of order 1 to describe the influence of the pore geometry (see equation 4). This parameter has only a minor effect on the sound speed of the fast wave and has been put equal to 1 in the rest of this study.

The bulk modulus $\mathrm{K}_{\mathrm{b}}$ and the shear modulus $\mathrm{N}$ (or equivalently the two Lamé constants) of the frame are the most difficult to measure. However, because of the approximation made in the equation 5 , the elastic moduli of the frame intervene only as the combination $K_{b}+4 / 3 N$, the value of which can be determined with the following experiment.

The liquid is drained from the pores and replaced by air. Due to the tremendous difference in density between the frame and air, partial decoupling of the Biot waves occurs ${ }^{3}$. The slow wave propagates in the fluid and the fluid particles do not have enough mass to generate a motion in the heavy solid frame. The fast wave travels in the solid frame and some air particles move along with the frame. The velocity of the fast wave will approximate the velocity in the frame as measured in vacuum and is given by:

$$
V^{2}=\frac{K_{b}+\frac{4}{3} N}{(1-h) \rho_{s}} \text {. }
$$

Measuring the pulse transit time on a sample with the pores filled with air results in a value for $\mathrm{K}_{\mathrm{b}}+4 / 3 \mathrm{~N}$.

\section{Measuring results}

The different parameters have been measured on 8 samples of bovine trabecular bone. The samples were cylinder shaped with a diameter of $3 \mathrm{~cm}$ and a length varying between 1.9 and 4.4 $\mathrm{cm}$. The trabeculae appeared to be randomly oriented and all samples were fairly homogeneous. The measuring results of the different parameters are given in Table 1.

Table I. The different parameters of the samples

\begin{tabular}{||l|l|l|l|l|l|l||}
\hline $\begin{array}{l}\text { length 1 } \\
(\mathrm{m})\end{array}$ & $\begin{array}{l}\text { density } \\
\left(\mathrm{kg} / \mathrm{m}^{3}\right)\end{array}$ & $\begin{array}{l}\text { porosity } \\
\mathrm{h}\end{array}$ & $\begin{array}{l}\text { tortuosity } \\
\alpha\end{array}$ & $\begin{array}{l}\text { permea- } \\
\text { bility } \\
\eta / b \\
\left(\mathrm{Ns} / \mathrm{m}^{4}\right)\end{array}$ & $\begin{array}{l}\text { elasticity } \\
\mathrm{K}_{\mathrm{b}}+4 / 3 \mathrm{~N} \\
10^{9} \mathrm{~N} / \mathrm{m}^{2}\end{array}$ \\
\hline 1 & 0.0188 & 348 & 0.86 & 1.80 & 699571 & 1.35 \\
2 & 0.0314 & 426 & 0.71 & 1.65 & 2528831 & 1.75 \\
3 & 0.0432 & 332 & 0.75 & 1.33 & 478879 & 1.05 \\
4 & 0.0395 & 493 & 0.69 & 1.44 & 935780 & 2.60 \\
5 & 0.0430 & 565 & 0.66 & 1.26 & 1357559 & 3.01 \\
6 & 0.0444 & 809 & 0.59 & 2.64 & 9883805 & 3.41 \\
7 & 0.0509 & 511 & 0.70 & 1.32 & 1068468 & 2.66 \\
8 & 0.0201 & 579 & 0.62 & 1.80 & 4051907 & 3.39 \\
\hline
\end{tabular}

The velocity of the fast compressional wave of the water saturated samples has been measured at three different frequencies by measuring the pulse transit time with two identical transducers attached to each face of the cylinder samples. The results, together with the predicti- 
ons from equation (1) and the data from Table I are given in Figure 1.

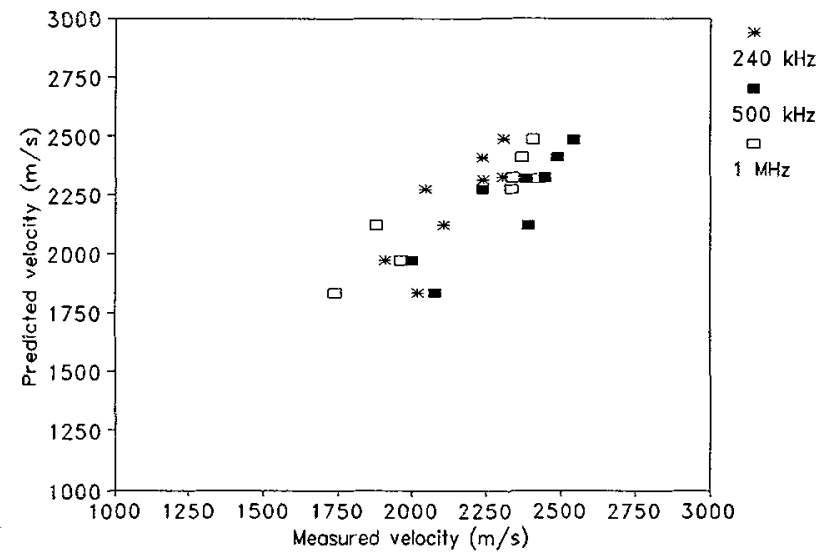

Figure 1. Velocity of the fast compressional wave compared to predictions of the Biot theory.

These results indicate a satisfactory agreement between theory and experiment.

\section{Conclusion}

It has been shown that the propagation of ultrasonic pulses through bovine trabecular bone can be adequately described using Biot's theory. The different parameters occurring in the theory have been measured independently and the calculations have been compared with measured velocities of water saturated bone samples. The theory should allow to study a change in structural parameters on the sound velocity (see ref 8 ) and can therefore be used to interpret ultrasonic measurements on bone samples.

\section{References}

1. M.A. Biot, "Theory of propagation of elastic waves in a fluid saturated porous solid, I Low frequency range", J. Acoust. Soc. Am., Vol. 28 (1956), 168-178.

2. M.A. Biot, "Theory of propagation of elastic waves in a fluid saturated porous solid, II High frequency range", J. Acoust. Soc. Am., Vol. 28 (1956), 179-191.

3. J.F. Allard, Propagation of sound in porous media (Elsevier Applied Science London 1993).

4 T.J. Plona, "Observation of a second bulk compressional wave in a porous medium at ultrasonic frequencies", Appl. Phys. Lett 36, (1980), 256-261.

5. J.F. Allard, C. Depollier, A. L'Espérance, "Observation of the Biot slow wave in a foam of high flow resistance at acoustic frequencies", J. Appl. Phys., 59 (1986), 3367-370.

6. R. Lakes, H.S. Yoon, J.L. Katz, "Slow compressional wave propagation in wet human and bovine cortical bone", Nature, April 1983, p. 513-515.

7. J.L. Williams, "Ultrasonic wave propagation in cancellous and cortical bone : prediction of some experimental results by Biot's theory", J. Acoust. Soc. Am., 91 (1992), 1106-1112.

8. M.Baldini, "Charactérisation ultrasonore des tissues osseux" Thèse de Doctorat, Université Francois Rabelais, Académie d' Orléans-Tours. 